\title{
Uma Investigação sobre a Neutralidade da Moeda no Brasil
}

\section{An Investigation on the Neutrality of Money in Brazil}

\author{
Renato Silverio Campos* \\ Alex Luiz Ferreira** \\ Reginaldo Pinto Nogueira Junior***
}

\begin{abstract}
Resumo: Este artigo investiga empiricamente a hipótese da neutralidade da moeda no longo prazo para o Brasil. Ao contrário de outros trabalhos, neste estudo não se partiu do pressuposto de que a velocidade da moeda é constante, sendo essa suposição também investigada. Foram coletados dados anuais da oferta nominal de moeda (Mo e M4), o nível de preços e o PIB real para o período de 1946 a 2008, para o teste com M0, e de 1970 a 2008 para o teste de robustez com o M4, sendo aplicados testes de integração das variáveis (com destaque para o estudo de estacionaridade da velocidade de circulação da moeda) e de cointegração, além de testes de exogeneidade. Os principais resultados encontrados mostram que (i) a velocidade de circulação da moeda pode ser considerada constante apenas controlando-se para a presença de quebras estruturais, e (ii) o PIB real é exógeno. Dessa forma, este trabalho apresenta evidências favoráveis à hipótese da neutralidade da moeda.
\end{abstract}

Palavras-chave: Neutralidade da moeda. Exogeneidade. Velocidade de circulação da moeda.

Abstract: This paper carries out an empirical investigation on the hypothesis of the long run neutrality of money for Brazil. Unlike previous studies, we did not assume that the velocity of money is constant and applied tests to check this hypothesis as well. We used annual data on the nominal money supply (Mo and M4), the price level and real GDP for Brazil. The sample period spans from 1946 to 2008 when we use data on M0 and from 1970 to 2008 when we use data on M4. We used cointegration and unit root tests (giving especial emphasis to the dynamic properties of the velocity of money), and exogeneity tests. Our results showed that

\footnotetext{
* Doutorando em Economia pelo Centro de Desenvolvimento e Planejamento Regional (Cedeplar) da Universidade Federal de Minas Gerais (UFMG). E-mail: renatocampos@cedeplar.ufmg.br

* * Professor doutor (PhD) da Faculdade de Economia, Administração e Contabilidade de Ribeirão Preto (FEA-RP) da Universidade de São Paulo (USP). E-mail: alexferreira@usp.br

*** Professor adjunto e coordenador da graduação em Relações Internacionais do IBMEC Minas Gerais. E-mail: reginaldo.nogueira@ibmecmg.br
} 
(i) the velocity of money can be treated as a constant only in the presence of structural breaks, and (ii) the real GDP is exogenous. Thefore, this paper provides supporting evidence for the hypothesis of neutrality of money.

Keywords: Neutrality of money. Exogeneity. Velocity of circulation of money.

JEL Classification: E31; E32; E41; E51.

\section{Introdução}

Fundamentada na concepção teórica da Economia Clássica, a hipótese da neutralidade da moeda no longo prazo diz que uma mudança permanente na quantidade de moeda não surte efeito nas variáveis reais da economia no longo prazo, tais como produto, nível de emprego, juros real, preços relativos, entre outros, tendo efeito apenas nas variáveis nominais, como nível de preços, juros nominais, etc. A neutralidade monetária surge como consequência teórica do pressuposto de que é o lado da oferta que determina o nível de produção na economia ${ }^{1}$.

As divergências entre as teorias modernas que tratam da neutralidade da moeda apoiam-se na dimensão temporal sob a qual agem os mecanismos de ajustamento de mercado. De forma geral, pode-se afirmar que, no curto prazo, tanto o nível de produto como o emprego podem ser estimulados por políticas de demanda agregada imprevistas, no caso dos novos-clássicos. Entretanto, no longo prazo, prevalece a noção de que os níveis de emprego e produto dependem das condições de produtividade e da disponibilidade dos fatores de produção ${ }^{2}$. Os novos-keynesianos, por sua vez, procuram explicar como pequenas rigidezes são importantes para determinar a inclinação positiva da curva de oferta de curtoprazo que, por consequência, podem promover desequilíbrios em alguns mercados, especialmente no mercado de trabalho. Essas rigidezes poderiam, portanto, explicar a não-neutralidade da moeda no curto prazo (BALL; MANKIW, 1994).

Contudo, existem algumas teorias que indicam que a política monetária pode vir a influenciar variáveis reais, tais como o PIB real mesmo no longo-prazo (ver, por exemplo, SUMMERS, 1981). Nesses trabalhos, o crescimento monetário e

1 Segundo essa hipótese, o crescimento de longo prazo depende exclusivamente de fatores nãomonetários. Essa hipótese pode ser derivada, por exemplo, da teoria quantitativa da moeda ou de uma função de produção padrão, ideias centrais à teoria econômica. Se variáveis monetárias não impactam variáveis reais no longo-prazo, torna-se curioso entender o porquê da grande preocupação acadêmica e das autoridades econômicas sobre o movimento dos preços. A justificativa mais usual é que a inflação reduz o bem-estar da população causando distorções que interferem na distribuição da renda, além do custo político (ver Blanchard e Fisher (1996, p. 569) e Romer (2005, cap. 10, item 10.9).

2 Não é objetivo do presente artigo identificar as diversas contribuições teóricas dessa linha de pesquisa desde a sua concepção nos anos 1970 e 1980, mas simplesmente enfatizar a neutralidade da moeda como uma característica comum a esses modelos. Para uma resenha sobre o tema e referências mais abrangentes, ver Magalhães (2005). 
a inflação podem atuar como um imposto sobre o investimento e, assim, gerar um efeito sobre o produto. De fato, o efeito Tobin ${ }^{3}$ está associado ao fato de a inflação representar um estímulo à acumulação de capital, uma vez que ela desestimula a retenção de moeda (saldos monetários reais). De modo intuitivo, a taxa de inflação representa um custo para a retenção de moeda, dado pelo seu impacto nos juros nominais. Um aumento na taxa de inflação, por reduzir a atratividade e o retorno da moeda, diminui o interesse dos indivíduos em alocarem suas riquezas nesta opção e torna mais atrativo o investimento em capital. Dessa forma, identifica-se uma relação positiva entre inflação e acumulação de capital.

No Brasil, sabe-se que o Banco Central, por meio do COPOM, determina as taxas de juros nominais com o objetivo de manter a inflação e suas expectativas dentro do alvo escolhido pelo sistema de metas. Assim, se o crescimento da demanda agregada ameaça a obtenção do alvo, o COPOM tende a aumentar a taxa de juros. Da mesma forma, se o nível de demanda agregada for tal que a inflação esperada se encontre abaixo da meta, o COPOM diminuiria os juros. No curto prazo entende-se que há um dilema entre emprego e o nível de preços (inflação), do tipo colocado pela curva de Phillips, ou seja, o Banco Central reagiria aos desvios do nível de produto com relação ao produto potencial na medida em que esses desvios possuíssem informações sobre o nível de preços futuro. Assim, um objetivo - talvez implícito - da política monetária é suavizar as flutuações do ciclo de negócios em torno da tendência de crescimento de longo prazo, visando diminuir as perdas de bem-estar da inflação. A ideia comum é a de que as intervenções das autoridades monetárias no mercado de moeda e de títulos de curto prazo não afetam o longo prazo.

A contrapartida da elevação da taxa de juros é a diminuição da oferta monetária, supondo a velocidade ${ }^{4}$ da moeda constante $(V)$. Na teoria clássica, $V$ é considerado relativamente estável ou constante no curto prazo, já que depende de alguns parâmetros que se modificam lentamente, tais como o comportamento do consumidor (por exemplo, devido a uma maior utilização de cheques e cartões de crédito). Portanto, a hipótese de constância da velocidade de circulação da moeda deve ser investigada a fim de não incorrer em um viés por omissão de variável relevante, o que poderia ocasionar em certa instabilidade para o modelo

3 Tobin (1965) enfatizou em seu trabalho outro fator importante do crescimento econômico: as decisões de alocação de riqueza. Para isso analisou as escolhas de portfólio entre capital, remunerado por sua produtividade marginal e moeda, simplificada por um único bem. Dessa forma, e de modo intuitivo, a taxa de inflação representa um custo para retenção de moeda dado seu impacto nos juros nominais. Um aumento na taxa de inflação, por reduzir a atratividade e o retorno da moeda, diminui o interesse dos indivíduos em alocarem suas riquezas nesta opção e torna mais atrativo o investimento em capital. Assim, identifica-se uma relação positiva entre inflação e acumulação de capital.

$4 \quad$ Também chamada de velocidade-renda da moeda, $V$ é a quantidade de transações que uma unidade monetária permite durante certo período de tempo. 
estimado. Desta forma, a principal contribuição deste trabalho é a investigação da hipótese de neutralidade da moeda e da constância de $V$ cobrindo dados de um período no qual a política monetária foi muito mais ativa no combate à inflação e, por hipótese, com efeitos mais acentuados sobre a produção e renda.

Diante do exposto, este trabalho foi realizado com o objetivo de investigar empiricamente a hipótese da neutralidade da moeda no longo prazo para o Brasil, complementando a série de dados de pesquisas anteriores para o período mais recente de estabilidade monetária. Nesse sentido, o presente artigo complementa trabalhos como os de, por exemplo, Nakane (1994) e Marques (2003). Para atender a esse objetivo foram utilizadas metodologias convencionais de estudos em séries de tempo: testes de integração e cointegração, além de testes de exogeneidade. Os resultados encontrados sugerem que a velocidade da moeda pode ser tratada como constante apenas controlando-se para quebras estruturais, e que o PIB real é exógeno. Nesse sentido, o trabalho oferece algum suporte à teoria econômica convencional.

\section{Referencial Teórico}

A hipótese da neutralidade da moeda tem como marco teórico a Teoria Quantitativa da Moeda (TQM), que é fundamentada na equação de trocas de Fisher, supondo que a velocidade-renda da moeda é constante, sendo o produto real determinado exogenamente por variáveis não-monetárias, tais como a tecnologia, o estoque de capital e a oferta de trabalho. Para ser válida a perfeita proporcionalidade entre oferta monetária e nível de preços, é preciso assumir a total flexibilidade dos preços e salários.

Com base na TQM, o modelo teórico que postula uma relação de longo prazo entre moeda e produto é derivado da Equação Quantitativa da Moeda (EQM), apresentada a seguir:

$$
M_{t} V_{t}=P_{t} Y_{t}
$$

em que $P$ é o nível de preços, $Y$ é o produto real, $M$ e $V$ são a oferta monetária e a velocidade de circulação da moeda, respectivamente. O subscrito $t$ indica o tempo.

A perfeita atuação dos mecanismos de mercado e a hipótese de expectativas racionais criam os canais necessários que possibilitam a resposta imediata dos preços a qualquer variação na oferta monetária. A resposta dos preços aos aumentos no estoque de moeda não permite sua contrapartida nos saldos monetários reais, mantendo o nível da atividade econômica inalterado, representado pela curva de oferta agregada verticalmente inclinada e fixa no pleno emprego.

Dessa forma, a política monetária, no modelo clássico, é ineficaz na determinação do produto. A TQM, portanto, formaliza a neutralidade monetária como 
uma elevação proporcional nos preços derivada de uma elevação no estoque de moeda. A política monetária só teria alguma influência sobre variáveis reais caso houvesse alguma imperfeição nos mercados, o que não é considerado no modelo clássico.

Do lado empírico, uma das abordagens mais antigas e, talvez, a pioneira neste tema é a regressão do produto e da moeda, conhecida por equação de St. Louis (ver ROMER, 2005). Porém, vários problemas foram discutidos em relação a essa abordagem. Como exemplo, o fato de que tal equação não revela uma evidência robusta para corroborar a influência dos agregados monetários sobre a teoria de flutuações reais, principalmente porque a causalidade pode ser no sentido do produto para a moeda em vez de ser da moeda para o produto, uma hipótese formalizada por King e Plosser (1984).

O desejo de obter uma evidência mais robusta sobre o efeito da política monetária sobre o produto real motivou um série de trabalhos que reexaminam a relação entre política monetária e a economia. Muitos desses trabalhos foram feitos nos contextos de vetores autorregressivos (VAR), causalidade no sentido de Granger e posteriormente pelas abordagens de Fisher e Seater (1993) e King e Watson (1997).

Os primeiros sistemas VAR desenvolvidos consideravam pouca ou nenhuma estrutura para o sistema. Dessa forma, os estudos das relações entre moeda e produto sofriam dos mesmos problemas da equação de St. Louis: variáveis omitidas, causalidade reversa e choques históricos de demanda (COOLEY; LEROY, 1985).

No sentido de causalidade, Hayo (1999) discutiu largamente esta metodologia e apresentou algumas suposições em relação a testes de causalidade no sentido de Granger. Para este autor, e para dados norte-americanos, em modelos com apenas duas variáveis, a moeda irá causar o produto. Adicionando-se outras variáveis (preços e taxa de juros), a significância estatística do efeito da moeda sobre o produto será menor.

As abordagens de Fisher e Seater (1993) e King e Watson (1997) consistem em um modelo macroeconômico que seja linear em ambas as variáveis observadas e nos choques estruturais. O teste é baseado no seguinte modelo autoregressivo bivariado de produto e moeda (assumindo que a taxa de crescimento de ambos, produto e moeda, são estacionárias):

$$
\begin{aligned}
& \Delta y_{t}=\lambda_{y m} \Delta m_{t}+\sum_{j=1}^{p} \alpha_{j, y y} \Delta y_{t-j}+\sum_{j=1}^{p} \alpha_{j, y m} \Delta m_{t-j}+\varepsilon_{t}^{\eta} \\
& \Delta m_{t}=\lambda_{m y} \Delta y_{t}+\sum_{j=1}^{p} \alpha_{j, m y} \Delta y_{t-j}+\sum_{j=1}^{p} \alpha_{j, m m} \Delta m_{t-j}+\varepsilon_{t}^{m}
\end{aligned}
$$


Sendo $y_{\mathrm{t}}$ o logaritmo do produto e $m_{\mathrm{t}}$ o logaritmo do agregado monetário. Fisher e Seater (1993) ${ }^{5}$ e King e Watson (1997), partem do princípio de que modelos macroeconômicos mais robustos incluem algumas outras variáveis importantes, choques além do $\varepsilon_{t}^{m}$ (choques monetários) são incorporados para capturar outras fontes de flutuações. Ainda, $\varepsilon_{t}^{n}$ é um vetor de choques, que não seja o choque de moeda, que afeta o produto.

Identificar um VAR de $n$ variáveis requer $n \times(n-1)$ restrições a priori, assim o número de restrições necessárias cresce de acordo com a quantidade de choques estruturais. Para essa metodologia, quando $n=2$, apenas duas restrições de identificação $0^{6}$ sa necessárias. O custo desta simplificação é que alguns dos resultados podem estar contaminados pelo viés de omissão de variáveis, como o nível de preços.

Vale ser ressaltado também que a abordagem acima parte da hipótese de que $y_{t}$ e $m_{t}$ são não cointegradas, o que é estranho à TQM (pelo motivo transacional, a moeda depende da renda). Segundo Fisher e Seater (1993) se as séries do produto e da moeda são não estacionários e cointegradas, logo um processo de Vetor Auto Regressivo (VAR) de ordem finita em primeira diferença não existe e isto, por si só, torna-se suficiente para rejeitar o comportamento de neutralidade no longo prazo. Este problema acontece, em parte, porque os Mínimos Quadrados Ordinários $(\mathrm{MQO})$ incorrem em um viés quando uma variável potencialmente significante (o termo de correção de erro) é omitida do modelo.

Vários trabalhos empíricos testaram a hipótese da neutralidade da moeda utilizando as abordagens de Fisher e Seater (1993) e King e Watson (1997), apresentadas acima. Citando apenas os mais relevantes, seguindo a abordagem de Fisher e Seater (1993), Coe e Nasson (2002) aplicaram essa metodologia para dados do Canadá, Austrália, Estados Unidos e o Reino Unido e encontraram fraco suporte para a neutralidade de longo prazo. Já Serletis e Koustas (1998) utilizaram a abordagem de King e Watson (1997) e dados de baixa frequência do produto real e da moeda para dez economias desenvolvidas, e encontraram evidências que suportam a hipótese de neutralidade.

Em relação aos testes de neutralidade monetária, pouca atenção foi dada a países em desenvolvimento. Para o Brasil, as contribuições de Fernandes e Toro (2005) são mais recentes. Os autores estimaram o mecanismo de transmissão monetária para o Brasil pós-Real utilizando um modelo VAR cointegrado, identifi-

5 Fischer e Seater (1993) formalizaram o conceito de neutralidade de longo prazo da seguinte forma: "that permanent, exogenous changes to the level of the money supply ultimately leave the level of real variables and the nominal interest rate unchanged but ultimately lead to equiproportionate changes in the level of prices and other nominal variables", p.402 (itálico reproduzido do texto original).

6 A diferença básica entre as metodologias de Fisher e Seater (1993) e King e Watson (1997) estão exatamente na identificação do VAR e na imposição de restrições para a identificação do sistema. 
cando o vetor de cointegração como a relação de equilíbrio. Eles analisaram o período de novembro de 1994 a fevereiro de 2001, tratando as mudanças nas reservas internacionais e na taxa de câmbio como variáveis exógenas. Os resultados empíricos evidenciaram que o estoque real de moeda é uma tendência estocástica comum do sistema e que existem três relações de longo prazo. A primeira combina as curvas de Phillips e IS estabelecendo uma relação negativa entre o hiato do produto real e a taxa de juros real. A segunda define o estoque real de moeda como uma função positiva do produto e da inflação, mas negativa da taxa SELIC fixada pelo Banco Central. O terceiro vetor de cointegração identifica a regra de reação monetária do Banco Central para fixar a taxa de juros SELIC (FERNANDES; TORO, 2005).

Bae e Ratti (2000), por sua vez, utilizaram a metodologia de Fischer e Seater (1993), dados de baixa frequência (anual), o período de 1912 a 1995 e o agregado monetário M2 para testar a hipótese da neutralidade monetária no Brasil. Estes autores concluíram que o agregado monetário é uma série I (2) para o Brasil e, segundo a metodologia, possível de se testar apenas a hipótese de super-neutralidade $^{7}$ monetária. Dessa forma, os autores encontram evidências de que a moeda não é super-neutra.

\section{Análise Empírica}

A hipótese da neutralidade da moeda, fundamentada a partir da equação de trocas de Fisher, supõe que a velocidade-renda da moeda é constante, sendo o produto real determinado exogenamente por variáveis não-monetárias. Mas, hipótese de que o produto real é exógeno tem aderência aos dados no Brasil? Ou em outras palavras, é válida a hipótese de neutralidade da moeda?

\subsection{Base de Dados}

Os dados para tal investigação consistem de observações anuais dos agregados monetários Mo e M4, do Índice Geral de Preços - Disponibilidade Interna (IGP-DI), do Produto Interno Bruto (PIB) brasileiro e do deflator implícito do PIB.

Quanto aos agregados monetários, algumas considerações devem ser feitas. O Mo, que representa apenas o papel moeda em poder do público, será a principal referência desse artigo, uma vez que é a única medida de agregado monetário totalmente controlado pelo banco central, e por isso, sem a influência de multiplicadores bancários. Contudo, julgou-se necessário a investigação da neutralidade da moeda por outra medida de oferta monetária para se obter maior robustez

$7 \quad$ Fisher e Seater (1993 p. 402, grifo do autor) definiram superneutralidade como: "[...] that permanent, exogenous changes to the growth rate of the money supply ultimately lead to equal changes in the nominal interest rate and leave the level of real variables unchanged". 
nas conclusões. Esse teste de robustez será feito por meio do agregado M4, uma vez que esse, por ser uma medida mais abrangente de liquidez, deve estar mais correlacionado com o produto real conforme sugere a literatura internacional (ver ROMER, 2005, em especial o cap. 5, item 5.5).

É importante ressaltar ainda que, os agregados monetários brasileiros sofreram uma reformulação conceitual ao longo da série estudada. Tal fato fez com que a série do agregado M4 se alterasse a partir de julho de 2001.

Para contornar esse problema, a estratégia adotada nesse trabalho foi, a partir do momento em que há descontinuidade (julho de 2001) na série do M4 no conceito antigo, aplica-se apenas a taxa de crescimento do M4 no novo conceito. Dito de outra forma, aplicou-se a taxa de crescimento do M4 no novo conceito sobre o M4 no conceito antigo a partir de julho de 2001 para completar a amostra até 2008.

O estudo compreende o período de 1946 a 2008 para o modelo com M0, e de 1970 a 2008 para o modelo com M4. Os dados foram obtidos no IPEA, e em todas as séries foi aplicado o logaritmo natural.

É importante destacar que o período de análise, tanto para Mo quanto para M4, englobam distintos regimes monetários no Brasil, o que justifica o cuidado com a análise das quebras estruturais advindas de choques de políticas. Assim, os resultados encontrados, algumas vezes, podem refletir a instabilidade da economia brasileira nos períodos estudados.

Gráfico 1 - Logaritmo do produto real (LY); Logaritmo da oferta nominal de moeda (LM0) e do nível de preços (LP)

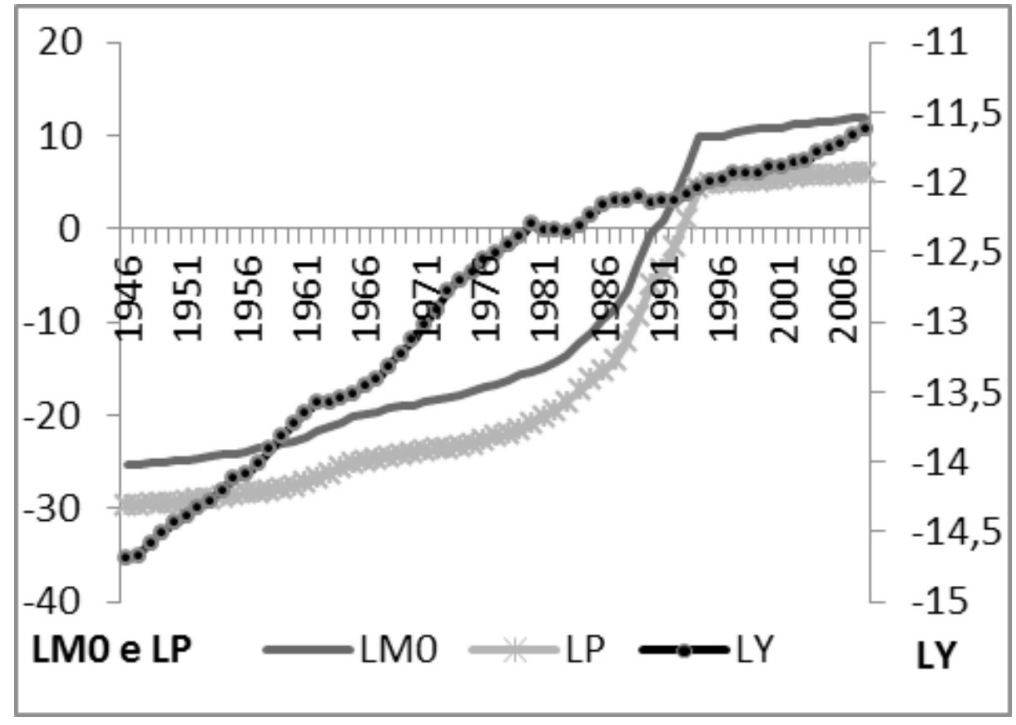

Fonte: Elaborado pelos autores. 
Gráfico 2 - Logaritmo da oferta nominal de moeda (LM4)

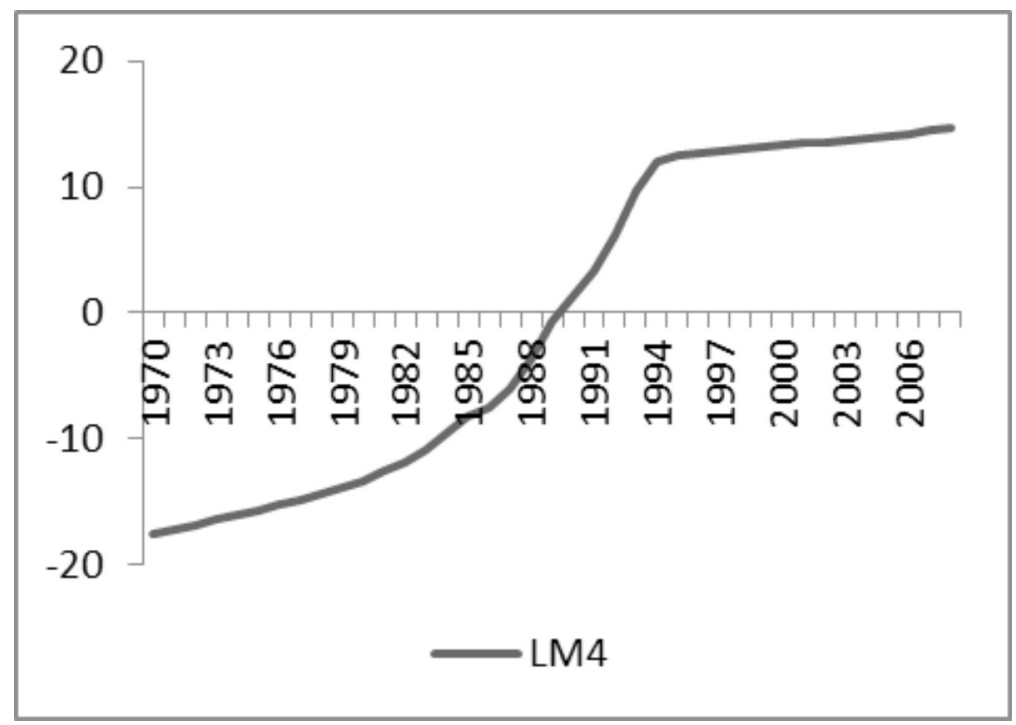

Fonte: Elaborado pelos autores.

\subsection{Vé constante?}

A velocidade de circulação da moeda é constante no Brasil durante o período amostral? Caso a resposta a essa pergunta seja negativa, a omissão de tal variável poderia implicar em um comportamento instável do modelo de neutralidade da moeda a ser estimado. Por isso, nessa seção procura-se investigar essa hipótese para suavizar a instabilidade que possa surgir da omissão de $V$.

Dessa forma, considerando a equação (1) em termos logaritmos ${ }^{8}$, a variável $V$ será construída da seguinte forma:

$$
u=-m+p+y
$$

Contudo, algumas implicações derivam dessa construção. A primeira delas é a de que $v$ por ser uma variável construída a partir de uma combinação linear das outras variáveis, a inclusão de $v$ no modelo poderia implicar em colinearidade perfeita, e dessa forma não faria sentido considerá-la.

A segunda implicação, e talvez a mais importante, seria observar que sendo $v$ construída da forma como apresentado acima, ou seja, por meio de uma combinação linear entre $y, m$ e $p$, seu comportamento (processo gerador de dados) seria algo parecido com a relação de cointegração entre as demais variáveis. Para perceber isso, considere um modelo em que apenas as variáveis da oferta nominal de moeda, nível de preços e produto são consideradas, o termo de correção de erro (ECM), que postula uma relação de cointegração entre as variáveis, e, portanto, uma combinação linear entre $m, p$ e $y$, terá um comportamento parecido com o de $v$. 
Dessa forma, a estratégia adotada neste trabalho foi investigar a estacionaridade da velocidade de circulação da moeda, e as possíveis fontes de não estacionaridade dessa variável. Identificadas essas possíveis quebras - advindas de desenvolvimentos tecnológicos (cartões de crédito, por exemplo) e da estabilização da economia - variáveis dummies serão incluídas no modelo, inclusive dentro do espaço de cointegração, a fim de "estacionarizar" o modelo de correção de erros.

A hipótese é que a constante irrestrita juntamente com as dummies represente $v$ no modelo. A hipótese feita de que $v$ terá um comportamento parecido com $o$ ECM será utilizada para modelar o espaço de cointegração.

Foram construídas duas séries para $v$, uma considerando o Mo (LVO) e outra considerando M4 (LV4). De acordo com o Gráfico 3, não está claro se estas séries são estacionárias ou não. Para $L V 0$ (modelo de referência), de fato, até 1980 parece haver um crescimento contínuo da série, seguido por um certo comportamento em torno de uma constante.

Gráfico 3 - Logaritmo da velocidade de circulação da moeda (LV)
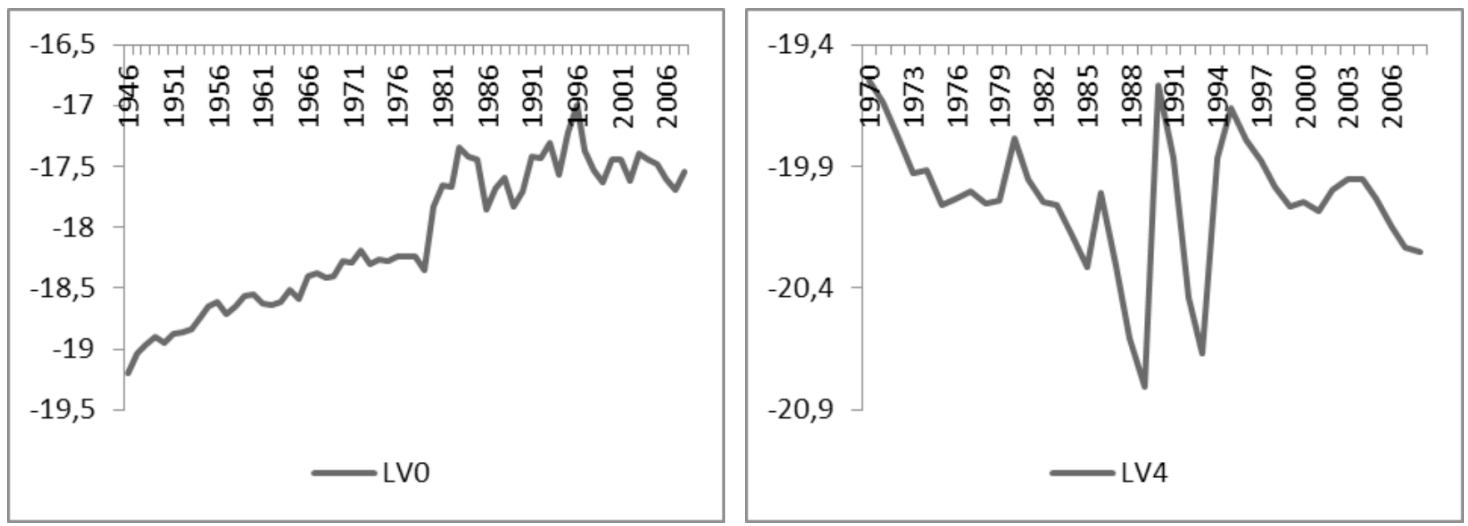

Fonte: Elaborado pelos autores.

Para uma conclusão mais robusta sobre a estacionaridade da série, serão aplicados, assim como nas outras variáveis, testes de raiz unitária do tipo $\mathrm{ADF}$, DF-GLS (ambos os testes partem da hipótese nula de que a série possui uma raiz unitária) e KPSS (que, ao contrário dos outros, a hipótese nula equivale à estacionaridade da série em questão), e seus resultados, bem como as especificações dos testes estão apresentados a seguir. 
Tabela 1 - Resultados dos testes de raiz unitária (v)

\begin{tabular}{lccccc}
\hline Variáveis & \multicolumn{2}{c}{ Especificação } & \multicolumn{2}{l}{ Estatística de teste } & \\
\hline & $\begin{array}{c}\text { Defasa- } \\
\text { gens }{ }^{1}\end{array}$ & $\begin{array}{c}\text { Componen- } \\
\text { tes Determi- } \\
\text { nistas }\end{array}$ & ADF & DF-GLS & KPSS \\
\hline $\mathrm{v}_{0}$ & 0 & - & $-1,387$ & $-0,3853$ & $5,7634^{* * *}$ \\
$\mathrm{v}_{4}$ & 1 & Constante & $-4,929^{* * *}$ & $-3,2284^{* * *}$ & 0,2448 \\
\hline
\end{tabular}

Fonte: Elaborada pelos autores.

Notas: 1. Começou com 4 defasagens.

${ }^{* * *}$ Rejeição da hipótese nula a 1\%, ${ }^{* *}$ Rejeição da hipótese nula a 5\%, " Rejeição da hipótese nula a $10 \%$

Para o modelo com M4 $\left(v_{4}\right)$ os testes parecem indicar que a série é estacionária no longo prazo. Quanto ao Mo $\left(v_{0}\right)$, os testes parecem implicar na presença de raiz unitária na série, o que indicaria que essa série é não estacionária. A estratégia aqui será identificar as fontes de não estacionaridade na série por meio do teste de raiz unitária com quebras estruturais de Lee e Strazicich (2003).

A vantagem do teste de Lee e Strazicich (2003), além da investigação endógena de duas possíveis quebras, é que o processo gerador de dados inclui quebras sob a hipótese nula e sob a alternativa de maneira consistente ${ }^{9}$, o que não leva a nenhuma ambiguidade com relação à tendência nas séries. Em outras palavras, rejeitar a nula de raiz unitária significa dizer que a série é tendência estacionária com presença de quebras estruturais. Suponha o seguinte processo gerador de dados:

$$
\begin{aligned}
& v_{t}=\delta^{\prime} Z_{t}+e_{t} \\
& e_{t}=\beta e_{t-1}+\varepsilon_{t}
\end{aligned}
$$

onde $Z_{t}$ é um vetor de variáveis exógenas, $\delta$ é um vetor de parâmetros e $\varepsilon_{t} \sim$ iid $N\left(0, \sigma^{2}\right)$. O modelo A (crash model) permite duas quebras no nível, incluindo duas dummies $D_{1 t}$ e $D_{2 t}$, e fica descrito por $Z_{t}=\left[1, t, D_{1 t}, D_{2 t}\right]$, onde $D_{j t}=1$ para $t \geq T_{B j}+$ $1, j=1,2$ e 0 caso contrário. $T_{B j}$ denota o momento em que a quebra acontece. $O$ modelo $C$ inclui duas quebras no nível e na tendência e é descrito por $Z_{t}=\left[1, t, D_{1}\right.$, $D_{2 t}, D T_{1 t}, D T_{2 t}$, onde $D T_{j t}=t-T_{B j}$ para $t \geq T_{B j}+1, j=1,2$ e 0 caso contrário (LEE; STRAZICICH, 2003).

Deve-se destacar que será assumido aqui que a velocidade de circulação da moeda possui (ou deveria possuir) um comportamento constante. Portanto, apenas quebras na constante do processo gerador de dados dessa variável serão permitidas, ou seja, será considerado para análise apenas o modelo A (crash model).

9 Para uma melhor apresentação da consistência da estimação e dos testes com suas respectivas distribuições, ver Lee e Strazicich (2003). 
Os resultados do teste, as especificações dos testes e as estatísticas de $t$ são apresentadas na Tabela 2. No teste, foi determinado o número de defasagens seguindo o critério que parte do geral para o específico.

Tabela 2 - v: Teste de raiz unitária minimun LM com duas quebras (Teste LS)

\begin{tabular}{lccccc}
\hline Variável & $\begin{array}{c}\text { Defasagem } \\
\text { ótima }\end{array}$ & $\begin{array}{c}\text { Estatística } \\
\text { de teste }\end{array}$ & \multicolumn{2}{c}{$\begin{array}{c}\text { Pontos de quebra } \\
\text { (estatistica de } \boldsymbol{t} \text { ) }\end{array}$} & $\begin{array}{c}\text { Quebras } \\
\text { significativas }\end{array}$ \\
\hline $\mathrm{V}_{0}$ & 0 & $-4,6093$ & $\begin{array}{c}1980 \\
(1,8125)\end{array}$ & $\begin{array}{c}1996 \\
(-1,5026)\end{array}$ & 1980 \\
\hline
\end{tabular}

Fonte: Elaborada pelos autores.

Começando com um máximo de 4 defasagens $(k=4)$, o procedimento investiga a significância da última defasagem, utilizando o valor da distribuição assintótica de uma normal com 10\% $(1,64)$. Os valores críticos são mostrados, na Tabela 3, para o teste de raiz unitária com duas quebras, sendo considerados e apresentados apenas os valores do modelo A. A Tabela 3 foi baseada em Lee e Strazicich (2003).

Tabela 3 - Valores críticos do teste de raiz unitária LM com duas quebras endógenas

\begin{tabular}{cccc}
\hline \multicolumn{5}{c}{ Modelo A } \\
\hline $\mathbf{1 \%}$ & $\mathbf{5 \%}$ & $\mathbf{1 0 \%}$ \\
\hline $\mathrm{LM}_{\mathrm{t}}$ & $-4,545$ & $-3,842$ & $-3,504$ \\
\hline
\end{tabular}

Fonte: Lee e Strazicich (2003).

De acordo com os resultados apresentados, conclui-se a favor da rejeição da hipótese nula. E, como já discutido anteriormente, rejeitar a nula de raiz unitária significa dizer que a série é estacionária com presença de quebras estruturais no intercepto, tendo, no presente caso, a única quebra significativa sido a de 1980. Portanto, uma dummy de quebra para 1980 será construída para ser incluída no modelo, afim de que, juntamente com a constante, represente $v$ no modelo com Mo.

Repare aqui que, como o teste proposto por Lee e Strazicich (2003) identifica endogenamente as quebras mais "fortes", a evidência encontrada que há apenas uma quebra significativa, indica que não há a necessidade de se utilizar uma metodologia de raiz unitária que permita mais quebras estruturais.

Essa quebra estrutural de $v$ em 1980 pode ser resultante do fato de que em 1979 o segundo choque do petróleo e a desvalorização cambial, decorrente do endividamento externo, elevaram a inflação para um patamar de $100 \%$ ao ano. A inflação permaneceu nesse patamar até 1983. Dessa forma, os agentes, preocupados com o alto custo em manter a moeda, aumentaram a circulação da mesma a fim de que a possível queda no poder de compra fosse minimizada. 


\subsection{Propriedades de Integração e Cointegração}

Para concluir sobre a ordem de integração da oferta nominal de moeda (M0 e M4), do índice de preços e do produto real, serão considerados neste trabalho, assim como já discutido anteriormente, os testes de raiz unitária conhecidos como ADF, DF-GLS e KPSS.

O teste $\mathrm{ADF}$ foi utilizado por permitir uma análise adequada das séries na presença de componentes deterministas. O teste DF-GLS propõe uma simples modificação do teste $\mathrm{ADF}$, na qual a série de tempo é previamente filtrada de seus componentes deterministas. E o teste KPSS inverte a hipótese nula, sendo essa equivalente à estacionaridades das séries.

As especificações dos testes, assim como as estatísticas dos testes são apresentadas na Tabela 4, lembrando que as variáveis estão em seu logaritmo natural, representadas pelas letras minúsculas.

A escolha das defasagens seguiu o critério que parte do geral para o específico. Estima-se a equação com um número elevado de defasagens e elimina-se uma a uma, de acordo com um teste- $F$, buscando evitar o viés de omissão de defasagens relevantes.

Tabela 4 - Resultados dos testes de raiz unitária

\begin{tabular}{|c|c|c|c|c|c|}
\hline \multirow[t]{2}{*}{ Variáveis } & \multicolumn{2}{|c|}{ Especificação } & \multicolumn{3}{|c|}{ Estatística de teste } \\
\hline & Defasagens $^{1}$ & $\begin{array}{l}\text { Componentes } \\
\text { deterministas }\end{array}$ & ADF & DF-GLS & KPSS \\
\hline $\mathrm{m}_{0}$ & 5 & $\begin{array}{l}\text { Constante e ten- } \\
\text { dência linear }\end{array}$ & $-2,4318$ & $-2,0656$ & $0,2322^{* * *}$ \\
\hline $\mathrm{m}_{4}$ & 3 & $\begin{array}{l}\text { Constante e ten- } \\
\text { dência linear }\end{array}$ & $-2,716$ & $-2,9784^{*}$ & $0,136^{*}$ \\
\hline $\mathrm{p}$ & 5 & $\begin{array}{l}\text { Constante e ten- } \\
\text { dência linear }\end{array}$ & $-2,1645$ & $-1,7549$ & $0,2325^{* * *}$ \\
\hline $\mathrm{y}$ & 2 & Constante & $-1,8777$ & 0,4711 & $2,1183^{* * * *}$ \\
\hline
\end{tabular}

Fonte: Elaborada pelos autores.

Notas: 1. Começou com 8 defasagens para $m_{0}, m_{4}$ e $p$, e 6 defasagens para o produto $(y)$. ***Rejeição da hipótese nula a 1\%, ${ }^{* *}$ Rejeição da hipótese nula a 5\%, "Rejeição da hipótese nula a $10 \%$

Primeiramente, para $\mathrm{o}_{4}$ percebe-se uma divergência nos resultados. Contudo, o teste DF-GLS têm seus valores críticos calculados para 50 observações e podem não ser robustos para uma amostra menor (como é o caso). Os outros testes (ADF e KPSS) parecem indicar para não estacionaridade da série. Dessa forma, o $m_{4}$ será tratado como uma série não estacionária no presente estudo.

Percebe-se ainda pela Tabela 4 que, para as outras três variáveis estudadas, não se rejeita a hipótese nula de que existe uma raiz unitária nas séries de tempo 
- testes ADF e DF-GLS. E ainda, considerando o teste KPSS, rejeita-se a hipótese nula de estacionaridade para as séries $m_{0}, p$ e $y$. Portanto, conclui-se que são todas variáveis I(1).

Para identificar a existência de cointegração, entre as séries de agregados monetários, índice de preços e o PIB real, será utilizado o procedimento de Johansen (1988). O método de Johansen pressupõe a correta especificação do modelo VAR, em nível, em relação aos termos deterministas e à estrutura de defasagens temporais das variáveis. As especificações em relação aos termos deterministas foram baseadas nas estatísticas descritivas das séries, $m_{0}, m_{4}, p$ e $y$, e, principalmente, nos testes de raiz unitária apresentados anteriormente.

Três pontos chamam a atenção e servem de subsídio para a formulação inicial do VAR; primeiramente, para os casos da oferta nominal de moeda $\left(m_{0}\right.$ e $\left.m_{4}\right)$ e nível de preços $(p)$ sob a hipótese nula de que as séries possuem uma raiz unitária (teste $\mathrm{ADF}$ ), essas variáveis possuem comportamento bastante semelhante de longo prazo, e tendência determinista quadrática em nível, uma vez que a presença de uma tendência linear sob a especificação ${ }^{10}$ do teste $\mathrm{ADF}$, implica uma tendência quadrática no nível da série; segundo, a inspeção gráfica das séries (Gráficos 1 e 2) indica a presença de uma quebra estrutural nas séries $m$ e $p$ (associada ao plano Real em 1994, que conseguiu controlar os altos índices de inflação dos anos antecessores), o que afeta os resultados dos testes acima e requer atenção maior para o comportamento dos resíduos do VAR, porém, vale ressaltar que os resíduos do VAR irão depender da combinação linear entre as variáveis, o que pode eliminar o efeito da quebra caso ela repercuta em ambas as séries; e por fim, a análise das fontes de não estacionaridade de $v$ apontou para a presença de uma quebra significativa na relação entre as variáveis. Essa quebra, portanto, deve ser incluída no VAR irrestrito a fim de modelar corretamente a velocidade da moeda.

Não foram investigados os efeitos de quebras estruturais sobre os resultados dos testes de raiz unitária das variáveis $m_{0}, m_{4}, p$ e y porque a análise econométrica seguiu em nível multivariado, o que permitiu uma avaliação mais robusta das fontes de não estacionaridade.

Dessa forma, para o modelo com o agregado monetário M0, estimou-se um VAR partindo de uma especificação mais geral, com presença de componentes deterministas quadráticos, seis defasagens e uma dummy de intercepto ( $\left.T_{B, 1}-1980\right)$ do tipo $D_{1 t}=1$ para $t \geq T_{B, 1}+1$, e 0 caso contrário, para captar o efeito da quebra estrutural sobre $v$ no ano de 1980. Para o teste de robustez (M4), iniciou-se com a mesma especificação excluída a dummy de intercepto.

Sob essas especificações, a tendência quadrática não se mostrou ser significativa tanto para $m_{0}$ e $m_{4}$ quanto para $p$. Uma possível explicação para isso seria de

10 A especificação do ADF com a presença de uma tendência é do tipo: $\Delta \mathrm{y}_{\mathrm{t}}=\mu+\delta \mathrm{t}+\alpha \mathrm{y}_{\mathrm{t}-1}+$ $\Sigma_{\mathrm{i}=1}^{\mathrm{p}} \lambda_{\mathrm{i}} \Delta \mathrm{y}_{\mathrm{t}-1}+\epsilon_{\mathrm{t}}$ 
que as séries, oferta nominal de moeda e nível de preços, compartilham da mesma tendência determinista quadrática, fazendo assim com que esse componente quadrático não apareça na relação entre as variáveis, ou em outras palavras, $m$ é suficiente para explicar o comportamento quadrático de $p$, e vice-versa. A análise dos gráficos 1 e 2 parecem corroborar com essa hipótese.

Em seguida, portanto, os VAR's foram reespecificados com a exclusão da tendência quadrática. Os critérios de informação FPE (Final Prediction Error), AIC (Akaike Information Criterion), SIC (Schwarz Information Criterion) e HQ (HannanQuinn Information Criterion) foram utilizados para escolha da defasagem adequada. No entanto, a informação dada pelos critérios deve ser confrontada com as advindas das demais características esperadas do VAR (normalidade e comportamento de ruído branco).

Os critérios de informação levam a escolhas distintas entre os sistemas e foram avaliados em conjunto com a análise do vetor de resíduos, de modo que estes se aproximem o máximo possível de ruídos brancos, conforme dados da Tabela 5.

Tabela 5 - Critérios de decisão para especificação do VAR irrestrito

\begin{tabular}{cccl}
\hline Critério & $\begin{array}{c}\text { Defasagem } \\
\text { Ótima }\end{array}$ & Análise dos Resíduos Vetoriais \\
\hline Mo & SC, HQ & 2 & $\begin{array}{l}\text { Não autocorrelacionados, Heteroscedástico e rejeição } \\
\text { de normalidade } \\
\text { Não autocorrelacionados, não Heteroscedástico e não } \\
\text { rejeição de normalidade }\end{array}$ \\
M4 & 5 & 2 & $\begin{array}{l}\text { Não autocorrelacionados, Heteroscedástico e não } \\
\text { rejeição de normalidade } \\
\text { Não autocorrelacionados, Não Heteroscedástico e } \\
\text { rejeição de normalidade }\end{array}$ \\
\hline
\end{tabular}

Fonte: Elaborada pelos autores.

Considerando-se o critério do comportamento dos resíduos, optou-se por adotar o VAR (em nível) com 5 defasagens, constante, tendência linear e uma dummy de quebra de intercepto para $1980\left(D_{1 t}=1\right.$ para $t \geq T_{B, 1}+1$ e 0 caso contrário) para o modelo com $\mathrm{MO}$.

Para M4, os resíduos não se mostraram "ruído branco" sob as especificações sugeridas pelos critérios de informação. Possivelmente, os vários choques de políticas econômicas enfrentados pelo Brasil durante o período amostral aliado às poucas observações disponíveis podem ter causado esses problemas nos resíduos. Dessa forma, optou-se pelo modelo com 5 defasagens, constante e tendência linear, por considerar a rejeição de normalidade um problema "menos" grave que o problema de heterocedasticidade.

Preferiu-se não tratar as quebras estruturais no VAR do modelo com o M4 por duas razões. Primeiro, o $v_{4}$ (que indica uma relação entre as outras variáveis) 
se mostrou estacionário sem a inclusão de quebras; e segundo, o mecanismo do autometrics ${ }^{11}$ de detecção de outliers indica apenas uma dummy de pulso, significativo apenas a $10 \%$, e que não corrige o problema de heterocedasticidade (para o modelo com 2 lags) e não normalidade (para o modelo com 5 lags).

A avaliação do comportamento dos resíduos, por meio de testes vetoriais conjuntos, indicou a relevância da quinta defasagem para os VAR's, que apresentou, para os testes de especificação, os resultados contidos na Tabela 6. Os modelos, assim especificados, mostraram estabilidade (todas as raízes características dentro do círculo unitário); ausência de autocorrelação nos resíduos e ausência de heteroscedasticidade. Para o modelo com Mo encontrou-se ainda a não rejeição da hipótese de normalidade conjunta.

Tabela 6 - Teste de especificação para o VAR

\begin{tabular}{lcccc}
\hline & \multicolumn{1}{c}{$\begin{array}{l}\text { Mo = 5 lags, constante, tendência linear e uma } \\
\text { dummy de quebra de intercepto para 1980. } \\
\text { Especificação }\end{array}$} & \begin{tabular}{l} 
M4 = 5 lags, constante e tendência linear. \\
\hline
\end{tabular} & \multicolumn{3}{c}{ Mo } & \multicolumn{2}{c}{ M4 } \\
\cline { 2 - 5 } Critério & Estatística & p-valor & Estatística & p-valor \\
\hline $\begin{array}{l}\text { Estabilidade: maior raiz caracterís- } \\
\text { tica }\end{array}$ & 0,9679 & & 0,9776 & \\
$\begin{array}{l}\text { Teste de Wald de exclusão da 5 } \\
\text { defasagem }\end{array}$ & 22,496 & $0,74 \%$ & 54,178 & 1,75 E-06\% \\
$\begin{array}{l}\text { Teste de normalidade conjunta } \\
\text { (Jarque-Bera) }\end{array}$ & 5,023 & $54,09 \%$ & 13,117 & $4,12 \%$ \\
$\begin{array}{l}\text { Teste de Heteroscedasticidade: Chi } 2 \\
\text { Teste de Autocorrelação (1-2): teste }\end{array}$ & 221,56 & $12,03 \%$ & 193,551 & $45,50 \%$ \\
F & 9,664 & $37,84 \%$ & 1,6163 & $13,17 \%$ \\
\hline
\end{tabular}

Fonte: Elaborada pelos autores.

Para prosseguir com o teste de cointegração, é preciso determinar cuidadosamente o modelo de cointegração a ser testado e a ordem de defasagem dos componentes. Contudo, o problema maior é determinar qual o modelo de cointegração utilizar. As possibilidades relacionam-se à existência de constante e tendência no nível do vetor $X_{t}$ (que no presente caso: $X_{t}=\left[y_{t}, m_{t}, p_{t}\right]$ ) e no vetor de cointegração. A partir da definição de qual deles cabe usar, definem-se os valores críticos a consultar (BUENO, 2008).

Como já discutido anteriormente, assume-se neste trabalho que o ECM se assemelha com o comportamento estocástico de $v$, devido à forma como este último foi construído. Sendo assim, como a velocidade de circulação da moeda, por hipótese, é uma constante, não será permitida uma tendência restrita ao ECM.

11 O autometrics será melhor discutido posteriormente. 
Dois pontos valem ser ressaltados aqui em relação aos testes para o modelo com Mo (referência principal desse estudo). Primeiro, é importante perceber que tirar a primeira diferença (ou seja, $D_{1 t}-D_{1 t-1}$ ) de uma dummy do tipo $D_{1 t}=1$ para $t$ $\geq T_{B, 1}+1$, e 0 caso contrário, para $T_{B 1}=1980$, encontra-se uma dummy de pulso do tipo: valor 1 apenas no ano indicado como a quebra (1981) e zero para o restante do período. Observe que o valor 1 apareceria no ano de 1981 e não em 1980, uma vez que a dummy de quebra de intercepto seria $D_{1 t}=1$ para $t \geq T_{B, 1}+1$; o segundo ponto importante, deve-se ao fato de que a primeira diferença de uma tendência linear gera uma constante, assim, uma constante irrestrita (que aparece tanto no vetor de cointegração quanto na dinâmica de curto prazo) é suficiente para modelar a tendência linear no nível das séries.

Apenas a título de notação, será utilizado neste trabalho que "DU1980" se trata da dummy de quebra no intercepto do tipo $D_{1 t}=1$ para $t \geq T_{B, 1}+1$, e 0 caso contrário, para $T_{B, 1}=1980$; e "D1981" a dummy de pulso que assume o valor 1 apenas no ano indicado como a quebra (1981) e zero para o restante do período.

Dessa forma, o modelo de cointegração a ser testado nesse trabalho para o modelo com Mo seria na forma de permitir uma constante dentro e fora do espaço de cointegração (constante irrestrita), a variável "DU1980" restrita ao vetor de cointegração e uma dummy de pulso (D1981). Para o modelo com M4, a especificação seria apenas com a constante irrestrita.

Têm-se, portanto:

$\Delta X_{t}=\alpha\left\{\beta^{\prime}\left[X_{t-1}+\mu_{0}+D U 1980\right]\right\}+\delta_{0}+\sum_{i=1}^{p-1} \Lambda_{i} \Delta X_{t-i}+\gamma D 1981+e_{t}$

Para a investigação com o Mo, e com o intuito de promover uma discussão mais robusta em relação ao modelo cointegrado descrito acima, optou-se partir, primeiramente, de modelos alternativos ao apresentado acima. Portanto, para investigar cointegração entre as variáveis, considere os seguintes modelos alternativos ao apresentado acima:

Modelo 1: 5 defasagens, constante irrestrita e DU1980 (quebra de intercepto) irrestrita.

Modelo 2: 5 defasagens, constante irrestrita e D1981 (pulso) exógena (apenas na dinâmica de curto prazo.

Assim como discutido em Marques (2003), as inclusões das variáveis dummies afetam as estatísticas calculadas e a distribuição assintótica dos testes. Com vista a este problema, buscou-se minimizar seus efeitos por meio de testes em modelos alternativos. A adição de dummies no modelo VAR provoca uma elevação no valor calculado das estatísticas do teste de cointegração e, com isso, induz ao problema da inferência estatística conhecido como Erro do Tipo I. Ou seja, a introdução de variáveis dummies no modelo induz à rejeição de hipótese nula, quando ela é verdadeira. A título de comparação define-se ainda um terceiro modelo sem nenhuma dummy, a saber: 
Modelo 3: 5 defasagens e constante irrestrita.

Para a investigação com M4, não julgou-se necessária a análise de modelos alternativos. Sendo considerado apenas o modelo especificado com uma constante irrestrita.

Na Tabela 7 observam-se os resultados dos testes de cointegração, lembrando que a estatística do traço testa a hipótese nula de existência de no máximo $k$ vetores cointegrantes contra a alternativa de que o número desses vetores é maior do que $k$.

Tabela 7 - Resultados de cointegração: teste do traço (Johansen)

\begin{tabular}{lcccc}
\hline & \multicolumn{3}{c}{ Mo } & \multirow{2}{*}{ Estatística do Traço } \\
\cline { 2 - 3 } & Modelo 1 & Modelo 2 & Modelo 3 & M4 \\
\hline $\mathrm{r}=0$ & $63,945^{*}$ & $31,603^{*}$ & $33,251^{*}$ & $58,664^{*}$ \\
$\mathrm{r} \leq 1$ & $16,819^{*}$ & 14,659 & $17,156^{*}$ & 10,317 \\
$\mathrm{r} \leq 2$ & 2,2859 & 0,0013 & 2,2045 & $4,801^{*}$ \\
\hline
\end{tabular}

Fonte: Elaborada pelos autores.

Nota: *Rejeição da hipótese nula a 5\%.

Os dados da Tabela 7 parecem validar a hipótese de que as variáveis cointegram. Contudo, tendo em vista o problema discutido anteriormente de que adição de dummies no modelo VAR provoca elevação no valor calculado das estatísticas do teste de cointegração e, com isso, induz ao Erro do Tipo I, neste trabalho assume-se a hipótese da TQM, na qual se atesta que a EQM possui apenas uma relação de longo prazo, e, portanto, apenas 1 vetor de cointegração. Sendo assim, na Tabela 8 são apresentados os vetores de cointegração estimados pela metodologia de Johansen. 


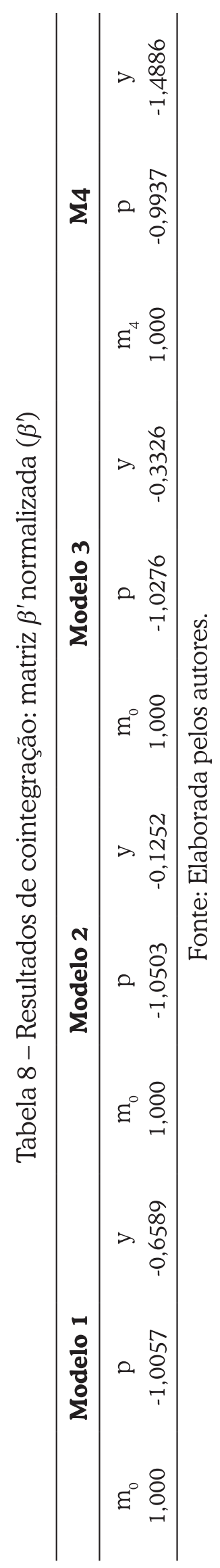

CAMPOS, R. S.; FERREIRA, A. L.; NOGUEIRA JUNIOR, R. P. Uma investigação sobre... 
Contudo, o primordial é modelar a relação de longo prazo, sem incorrer em um Erro do Tipo I, e, por isso, o modelo descrito na equação (5) seria o mais adequado aos nossos propósitos para o modelo com Mo. Sendo assim, a estratégia adotada aqui será com base em Nakane (1994). Vale ressaltar que $\beta^{\prime}$ representa um vetor cointegrante individual, isto é, uma combinação linear particular I(0) entre as variáveis. Por sua vez, $\alpha$ representa o conjunto de pesos com que os vetores cointegrantes individuais aparecem na respectiva equação.

Estimando-se o ECM para Mo (equação 6) e para o M4, obtém-se o seguinte:

$$
E C M_{\text {ot }}=m_{\text {ot }}-13,854-1,002 p_{t}-0,653 y_{t}+0,452 \text { DU1980 }
$$

$$
(0,004) \quad(0,041) \quad(0,095)
$$

$$
E C M_{4 t}=m_{4 t}-25,954-0,9937 p_{t}-1,4886 y_{t}
$$

$$
\text { (S.E) } \quad(0,002) \quad(0,079)
$$

Um ponto que merece atenção é o sentido dos sinais. Os sinais do ECM estão compatíveis com a construção de $v$, apresentada antes, fato este que mais uma vez reafirma a hipótese de que a relação de longo prazo entre as variáveis tem comportamento semelhante com a velocidade de circulação da moeda construída. O importante é perceber que, como a equação está normalizada para $m$, ou seja, assume-se que $m$ seja positivo, os sinais das variáveis parecem invertidos se comparados $\operatorname{com} v(v=-m+p+y)$.

Como o objetivo é de que o $E C M$, que representa os resíduos da relação de longo prazo entre as variáveis $m, p$ e $y$, seja uma combinação linear $I(0)$ entre as variáveis, vale apresentar os gráficos 4 e 5 das equações (6a) e (6b). Apenas para fins de comparação, foi analisado o comportamento do ECM do modelo 3 (gráfico 4 - ECM(3)) sem as dummies (DU1980 e D1981). Visualmente, a inclusão da dummy "DU1980" dentro do espaço de cointegração resulta em um ECM mais próximo de um comportamento do tipo $I(0)$, ou seja, estacionário. 


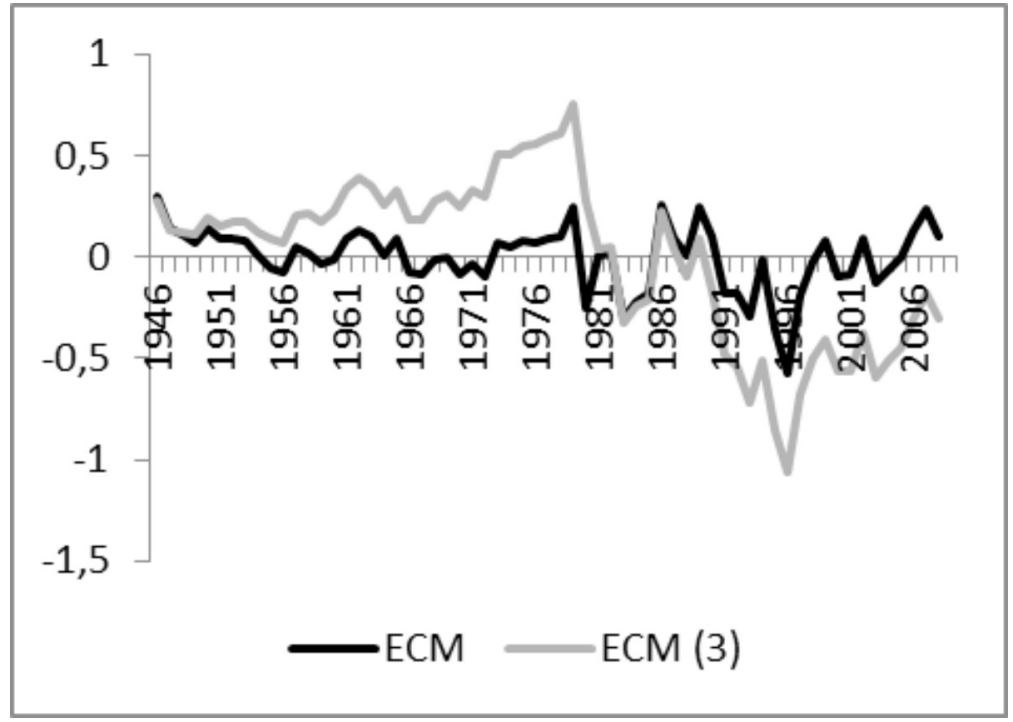

Fonte: Elaborado pelos autores.

\section{Gráfico 5 - Comportamento temporal do ECM (modelo com M4)}

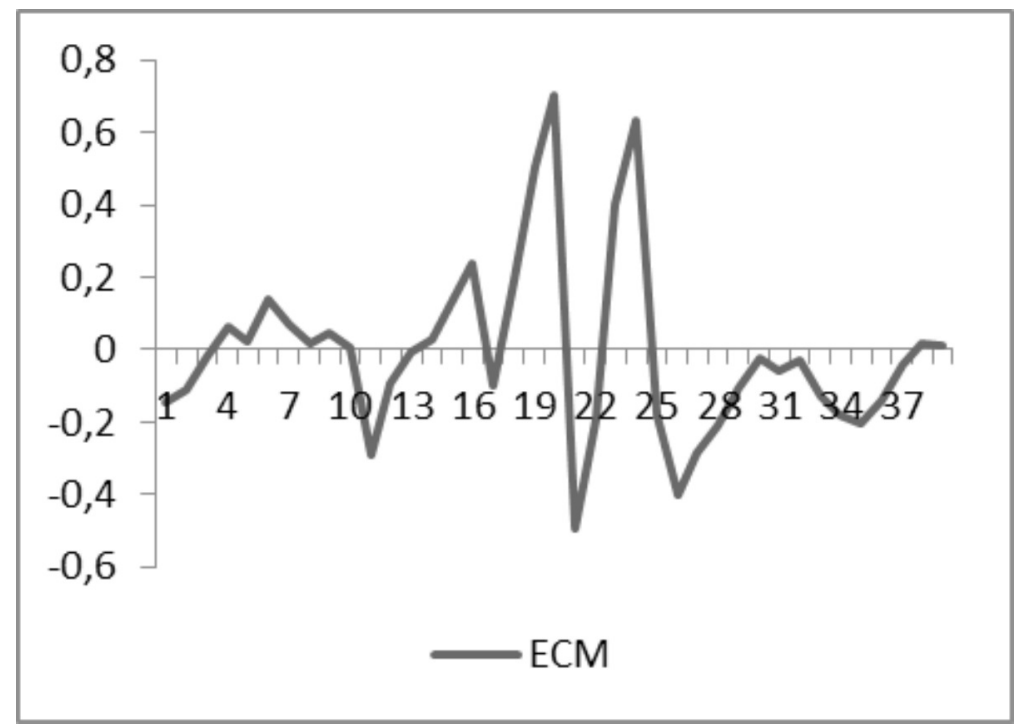

Fonte: Elaborado pelos autores.

Embora cointegração indique a presença de causalidade Granger, não fica especificada a direção da causalidade entre as variáveis. A direção da causalidade pode ser detectada por meio do Vetor de Correção de Erros (VEC) derivado dos vetores de cointegração de longo prazo, o qual implica que uma eventual mudança na variável dependente é função do nível de desequilíbrio na relação de cointegração, mudança esta capturada pelo termo de correção de erro.

Portanto, o VEC irrestrito foi modelado, para os dois modelos, com a variável dependente dada por $\Delta X_{t}$ (sendo $\left.\Delta X_{t}=\left[\Delta y_{t}, \Delta m_{t}, \Delta p\right]\right)$, com defasagens até a quarta ordem (para se manter coerente com a análise VAR, em que o termo em nível 
era de quinta ordem) e os termos deterministas compreendendo uma constante irrestrita (dentro e fora do espaço de cointegração).

Para o modelo com Mo incluem-se ainda a variável "DU1980" restrita ao vetor de cointegração e uma dummy de pulso (D1981).

\subsection{Testes de Exogeneidade para a Função da Oferta Nominal de Moeda}

Nesta seção serão realizados os testes de exogeneidade fraca, forte e de superexogeneidade. $\mathrm{O}$ objetivo aqui é analisar apenas o modelo condicional, aqui representado pela oferta nominal de moeda, para investigar a exogeneidade do produto real nesta função, assim como descrito pela TQM.

Assim como destacado por Castro e Cavalcanti (1997), a validade de analisar apenas o modelo condicional, ignorando o modelo marginal, depende de as informações contidas neste último não serem relevantes para os objetivos da análise. Diferentes objetivos requerem distintos conceitos de exogeneidade; assim, eficientes inferências estatísticas, previsões e simulações de política estão associadas, respectivamente, às noções de exogeneidade fraca, exogeneidade forte e superexogeneidade.

O modelo condicional é representado pela equação de oferta nominal de moeda. A partir dessa equação, os testes de exogeneidade relevantes dizem respeito à variável do produto real (modelo marginal), pois a validade da hipótese da neutralidade da moeda depende da exogeneidade de $y$ na função da oferta nominal de moeda.

\subsubsection{Testes de exogeneidade fraca e forte}

A importância de se verificar exogeneidade fraca decorre do viés de endogeneidade, ou seja, assume-se que uma variável é exógena ao modelo, quando, na verdade, ela não o é. A implicação disso é que, em modelos uniequacionais, quando se assume que as variáveis do lado direito são exógenas, se tal não for verdade, a equação pode ser melhorada por um sistema de equações, isto é, a estimação por uma equação não é eficiente (SACHSIDA, 1999).

Seguindo a definição de Engle, Hendry e Richard (1983), as variáveis são ditas exógenas fracas para determinados parâmetros de interesse se: a) tais parâ-

metros dependem exclusivamente dos parâmetros do modelo condicional e b) os parâmetros dos modelos condicional e marginal possuem variação liure — isto é, não estão sujeitos a restrições conjuntas. Sob tais condições, inferências relativas aos parâmetros de interesse podem ser realizadas a partir do modelo condicional, sem perda de informação relevante.

Assim como discutido em Nakane (1994), quando os parâmetros de interesse são os de longo prazo $\alpha \beta^{\prime}$, uma condição necessária e suficiente para a exogeneidade fraca é que a velocidade de ajustamento seja igual a zero $\left(\alpha_{y}=0\right)$, ou seja, 
o vetor de co-integração não deve aparecer no modelo marginal. Este é um teste alternativo para detectar exogeneidade fraca em um modelo, sugerido por Hendry e Mizon (1990). A ideia do teste é verificar a presença de termos de mecanismos de correção de erros em mais de uma equação do modelo. Como o termo de correção de erros envolve combinações lineares entre as variáveis do modelo, se um mesmo termo aparecer em mais de uma equação do sistema, certas restrições cruzadas entre tais equações estarão presentes, o que violaria a hipótese de variação livre entre os parâmetros, necessárias para que se tenha exogeneidade fraca.

O primeiro passo dessa seção é estimar equações para a oferta nominal de moeda (modelo condicional) e para o produto real (modelo marginal) a partir da EQM. Da análise univariada depreende-se que uma modelagem em termos de variações de $m_{0}, m_{4}$, p e y seria apropriada. Da análise de cointegração depreende-se que um termo de mecanismo de correção de erros deve fazer parte da equação. Os termos do mecanismo de correção de erros (ECM) seguem as equações $(7 \mathrm{a}, \mathrm{b})$.

Portanto, para a oferta nominal de moeda representada pelo Mo iniciou-se com um modelo de correção de erros irrestrito assim como apresentado na equação 9, com a variável dependente dada por $\Delta m_{0 t}$, com defasagens até a quarta ordem e os termos deterministas compreendendo uma constante e uma variável dummy de pulso (D1981), lembrando que a variável dummy de quebra de intercepto está incluída dentro do termo de correção de erro - ECM.

E para a oferta nominal de moeda representada pelo M4 iniciou-se com um modelo de correção de erros irrestrito com a variável dependente dada por $\Delta m_{4 t}$, com defasagens até a quarta ordem e uma constante.

Para a redução dos sistemas irrestritos descritos, utilizou-se o procedimento de seleção automática embutido no pacote econométrico Autometrics. Este algoritmo realiza uma seleção de modelo que vai do geral para o específico e é baseado na teoria de redução ${ }^{12}$. O Autometrics sugeriu um modelo com no máximo três defasagens para a oferta nominal de moeda. A partir dessa informação, utilizou-se testes-t e F para exclusão de variáveis e testes de autocorrelação serial dos resíduos e de heteroscedasticidade para redução do modelo. Dessa forma, os modelos irrestritos são reduzidos para as equações assim como descrito na Tabela 9, sendo esses os modelos condicionais.

12 Para uma discussão dessa teoria veja Krolzig e Hendry (2004). E para uma descrição do algoritmo veja Doornik (2009).

CAMPOS, R. S.; FERREIRA, A. L.; NOGUEIRA JUNIOR, R. P. Uma investigação sobre... 
Tabela 9 - Modelo condicional: equação da oferta nominal de moeda (DLM)

\begin{tabular}{|c|c|c|}
\hline \multirow[b]{2}{*}{ Variável } & \multicolumn{2}{|c|}{$\begin{array}{l}\text { Coeficiente } \\
\text { (erro-padrão) } \\
\text { [teste-t] }\end{array}$} \\
\hline & DLMO & DLM4 \\
\hline Constante & - & $\begin{array}{c}-0,2027 \\
(0,1416) \\
{[-1,43]}\end{array}$ \\
\hline $\operatorname{DLM}(-1)$ & $\begin{array}{c}0,09593 \\
(0,1221) \\
{[0,786]}\end{array}$ & $\begin{array}{c}0,341 \\
(0,4178) \\
{[0,816]}\end{array}$ \\
\hline $\operatorname{DLM}(-2)$ & - & $\begin{array}{l}-0,1616 \\
(0,3206) \\
{[-0,504]}\end{array}$ \\
\hline $\operatorname{DLM}(-3)$ & - & $\begin{array}{l}-0,1563 \\
(0,2702) \\
{[-0,578]}\end{array}$ \\
\hline DLP & $\begin{array}{c}1,08095 \\
(0,0348) \\
{[31,1]}\end{array}$ & $\begin{array}{c}1,2554 \\
(0,1334) \\
{[9,42]}\end{array}$ \\
\hline $\operatorname{DLP}(-1)$ & $\begin{array}{c}-0,1009 \\
(0,1384) \\
{[-0,73]}\end{array}$ & $\begin{array}{l}-0,2904 \\
(0,3759) \\
{[-0,773]}\end{array}$ \\
\hline $\operatorname{DLP}(-2)$ & $\begin{array}{l}-0,0547 \\
(0,048) \\
{[-1,14]}\end{array}$ & $\begin{array}{c}0,066 \\
(0,2827) \\
{[0,233]}\end{array}$ \\
\hline $\operatorname{DLP}(-3)$ & $\begin{array}{l}-0,0787 \\
(0,040) \\
{[-1,94]}\end{array}$ & $\begin{array}{c}0,0858 \\
(0,1992) \\
{[0,431]}\end{array}$ \\
\hline DLY & $\begin{array}{c}0,9788 \\
(0,2851) \\
{[3.43]}\end{array}$ & $\begin{array}{c}3,9618 \\
(1,303) \\
{[3,04]}\end{array}$ \\
\hline D1981 & $\begin{array}{c}-0,3685 \\
(0,1307) \\
{[-2,82]}\end{array}$ & - \\
\hline $\operatorname{ECM}(-1)$ & $\begin{array}{c}-0,8792 \\
(0,1508) \\
{[-5,83]}\end{array}$ & $\begin{array}{c}-1,6746 \\
(0,5936) \\
{[-2,82]}\end{array}$ \\
\hline $\begin{array}{l}\text { Autocorrelação 1-2 } \\
\text { [p-valor] }\end{array}$ & $0,0821[0,9213]$ & $0,9963[0,3846]$ \\
\hline Heterocedasticidade & $0,8933[0,2804]$ & $0,8036[0,6695]$ \\
\hline Normalidade & $6,4674\left[0,0394^{*}\right]$ & $4,3369[0,1144]$ \\
\hline
\end{tabular}

Fonte: Elaborada pelos autores.

Para a estimação do modelo marginal, aqui representado pela equação do produto real (Tabela 10), utilizou-se mais uma vez o recurso do autometrics. 
Para o produto real partiu-se de modelos de correção de erros irrestritos assim como já descrito para a oferta nominal de moeda, com a diferença de que as variáveis dependentes são dadas por $\Delta y_{0 t}$ e $\Delta y_{4 t}$.

Neste caso o Autometrics sugeriu uma defasagem máxima de quarta ordem, e mais uma vez, utilizando testes-t e $F$ para exclusão de variáveis, testes de autocorrelação serial dos resíduos e de heteroscedasticidade para redução do modelo, chegou-se a um modelo parcimonioso e com erros que possuem comportamento de ruído branco, reportado na Tabela 10.

Tabela 10 - Modelo marginal: equação do produto real (DLY)

\begin{tabular}{lcc}
\hline & \multicolumn{3}{c}{$\begin{array}{c}\text { Coeficiente } \\
\text { (erro-padrão) } \\
\text { [teste-t] }\end{array}$} \\
\hline Variável & DLY (M0) & DLY (M4) \\
\hline Constante & 0,0168 & 0,0165 \\
& $(0,0065)$ & $(0,008)$ \\
DLY (-1) & {$[2,58]$} & {$[1,93]$} \\
& 0,4589 & 0,2822 \\
DLY (-2) & $0,1117)$ & $0,1647)$ \\
& {$[4,11]$} & {$[1,71]$} \\
D1981 & $-0,2312$ & 0,2224 \\
& $(0,1104)$ & $(0,1583)$ \\
& {$[2,09]$} & {$[1,41]$} \\
Autocorrelação 1-2 & $-0,1158$ & - \\
[p-valor] & $0,0284)$ & $0,2419[0,7866]$ \\
Heterocedasticidade & {$[-4,08]$} & $0,5654[0,6897]$ \\
Normalidade & $0,0129[0,9872]$ & $4,3818[0,1118]$ \\
\hline
\end{tabular}

Fonte: Elaborada pelos autores.

O importante a reparar na Tabela 10 é que o termo de correção de erros foi excluído dos modelos por este não ser significativo. Sendo assim, a insignificância do $E C M_{t-1}$ resulta na evidência de que $y$ é fracamente exógena do ponto de vista do modelo testado neste trabalho, que tem como base teórica a EQM. Este resultado também é válido para o modelo com M4.

Já a finalidade de se testar se a variável do produto real é exogenamente forte em relação à equação da oferta nominal de moeda reside na capacidade de previsão do modelo. Seguindo Nakane (1994), se o produto real for exogenamente forte, então a equação condicional (oferta nominal de moeda) poderá ser utilizada para previsão. 
De acordo com Sachsida (1999), a propriedade da exogeneidade forte exige dois pré-requisitos: a) exogeneidade fraca da variável e b) não-causalidade no sentido de Granger. Já foi demonstrada a primeira exigência, ou seja, a de que o produto real é exogenamente fraco ao modelo. Portanto, para investigar a exogeneidade forte, basta apenas verificar se há causalidade no sentido de Granger.

Vale ressaltar que o teste de Granger-causalidade não determina se alguma variável é exógena ou não. O teste serve apenas para determinar a precedência temporal de uma variável sobre a outra. O teste de causalidade foi feito sobre os VEC's irrestritos, assim como já descritos anteriormente, e estão apresentados na Tabela 11.

Tabela 11 - Teste de causalidade Granger

\begin{tabular}{|c|c|c|c|c|}
\hline \multirow[b]{2}{*}{$\begin{array}{l}\text { Hipótese } \\
\text { Alternativa }\end{array}$} & \multicolumn{2}{|c|}{ Mo } & \multicolumn{2}{|c|}{ M4 } \\
\hline & $\begin{array}{l}\text { Estatística } \\
\text { Chi-sq }\end{array}$ & Probabilidade & $\begin{array}{l}\text { Estatística } \\
\text { Chi-sq }\end{array}$ & Probabilidade \\
\hline 1. $\mathrm{ECM}_{\mathrm{t}-1} \rightarrow \mathrm{m}$ & 0,963 & $34,1 \%$ & 1,219 & $26,96 \%$ \\
\hline 2. $\mathrm{ECM}_{\mathrm{t}-1} \rightarrow \mathrm{p}$ & 2,13 & $3,9 \%$ & 9,334 & $0,22 \%$ \\
\hline 3. $\mathrm{ECM}_{\mathrm{t}-1} \rightarrow \mathrm{y}$ & $-0,587$ & $56,0 \%$ & 0,318 & $57,30 \%$ \\
\hline 4. $\quad \mathrm{y} \rightarrow \mathrm{m}$ & 2,755 & $59,96 \%$ & 2,627 & $62,20 \%$ \\
\hline 5. $\mathrm{p} \rightarrow \mathrm{m}$ & 14,132 & $0,69 \%$ & 7,869 & $9,65 \%$ \\
\hline 6. $\quad \mathrm{m} \rightarrow \mathrm{p}$ & 8,501 & $7,46 \%$ & 28,638 & $0,00 \%$ \\
\hline 7. $y \rightarrow p$ & 4,116 & $39,06 \%$ & 5,116 & $27,56 \%$ \\
\hline
\end{tabular}

Fonte: Elaborada pelos autores.

Seguindo Granger, Huangb e Yang (2000), causalidade no sentido de Granger não pode ser rejeitada se o coeficiente do $E C M_{t-1}$ for significante e os valores defasados da variável de interesse forem conjuntamente significantes.

Sendo assim, o teste de causalidade para as funções do produto não fazem sentido aqui, uma vez que o $E C M_{t-1}$ não se mostrou significativo tanto no VEC's irrestritos quanto nos modelos marginais. Contudo, para as equações do nível de preços e da oferta nominal de moeda (seguindo as evidências encontradas na Tabela 9), o $E C M_{t-1}$ parecer ser significativo e, portanto, passível de teste de causalidade no sentido de Granger.

Para testar a exogeneidade forte do produto, é necessário verificar se o produto real $(y)$ causa, no sentido de Granger, a oferta nominal de moeda $(m)$, e checar se o contrário não é verdadeiro. De acordo com os resultados encontrados, a hipótese de exogeneidade forte do produto parece não ser válida, visto que a alternativa 4 da Tabela 11 mostra que $y$ não Granger causa $m$. Portanto, a evidência encontrada aqui não é conclusiva a respeito da exogeneidade forte do produto real no contexto da EQM. Outra evidência interessante é a simultaneidade entre níveis de preços e oferta nominal de moeda. 
Contudo, a análise seguirá no âmbito de modelos uniequacionais, ou seja, a investigação da hipótese da neutralidade da moeda e, por conseguinte da exogeneidade do produto real, será por meio do modelo condicional (oferta nominal de moeda) e do modelo marginal (produto real). Isto porque, os dados da Tabela 9 indicam uma relação contemporânea de $y$ com $m$. Talvez o grande número de defasagens necessárias para estabilizar o modelo e para "branquear" os resíduos, tenha prejudicado a inferência sobre a relação entre $y$ e $m$ no que diz respeito aos testes de causalidade.

\subsubsection{Teste de super-exogeneidade}

Com a preocupação de que os modelos especificados até aqui sofram de invariância estrutural advinda de planos econômicos ao longo do período amostral, partiu-se para uma análise de super-exogeneidade. De acordo com Sachsida (1999), esse teste permite a um modelo econométrico escapar da Crítica de Lucas. Lucas (1976) argumentou que, sob a hipótese se expectativas racionais, os modelos econométricos não poderiam ser utilizados com fins de formulação de políticas econômicas, pois, uma vez mudado o parâmetro de política, os agentes se readequariam à nova realidade, o que alteraria seu comportamento e, consequentemente, causaria mudanças nos parâmetros antes encontrados pelos modelos econométricos.

Os requisitos básicos para uma variável ser super-exógena são: a) exogeneidade fraca e b) invariância estrutural.

Para realizar o teste de super-exogeneidade, o primeiro passo consiste em estimar os modelos marginais $(y)$ - Tabela 10 - e salvar seus resíduos. No segundo passo, devem-se elevar os resíduos ao quadrado e incluí-los, bem como suas defasagens, no modelo condicional como variável explicativa. Por fim, checa-se a significância conjunta dessa variável. A intuição deste teste é que os erros do processo marginal não devem melhorar a estimativa no processo condicional. Caso contrário, ou seja, se o quadrado dos resíduos for significativo, isso implica que, quando ocorrerem quebras estruturais no modelo marginal (isto é, ocorrem saltos no tamanho do erro), tais alterações impactarão o modelo condicional. Com isso, quebras no modelo marginal estariam se propagando para o modelo condicional e, assim, não seria correto aceitar a hipótese de superexogeneidade para a variável do processo marginal. Este teste foi sugerido por Engle e Hendry (1993).

Desse modo, na Tabela 12 é explicitado o resultado da inclusão dos resíduos ao quadrado (e suas defasagens) do modelo marginal no modelo condicional. No que tange ao teste de superexogeneidade, o importante é a parte final da Tabela 12, isto é, o teste $F$ de exclusão de variáveis. Tal teste verifica a significância conjunta da variável $\hat{u}_{y, t}^{2}$ que nada mais é do que o resíduo ao quadrado do modelo marginal, aqui representado pela função do produto real $(y)$. Como pode ser observado, o teste de $F$ não rejeita a hipótese de que a variável $\hat{u}_{y, t}^{2}$ em seu conjunto 
(ou seja, com as defasagens), seja zero. Dado que tais variáveis são estatisticamente não significantes, o teste sobre a função da oferta nominal de moeda conclui pela aceitação da superexogeneidade do produto real sobre a oferta nominal de moeda, tanto para o modelo com o Mo quanto para o teste de robustez com o M4.

A ideia por trás deste teste é a de que os choques do modelo marginal não são compartilhados pelo modelo condicional, o que leva a conclusão de que a oferta nominal de moeda é invariante aos choques que afetam o produto real.

Tabela 12 - Teste de super-exogeneidade (DLM)

\begin{tabular}{|c|c|c|}
\hline \multirow[b]{2}{*}{ Variável } & \multicolumn{2}{|c|}{$\begin{array}{c}\text { Coeficiente } \\
\text { (erro-padrão) } \\
\text { [teste-t] }\end{array}$} \\
\hline & DLMO & DLM4 \\
\hline Constante & - & $\begin{array}{c}-0,1789 \\
(0,1687) \\
{[-1,06]}\end{array}$ \\
\hline $\operatorname{DLM}(-1)$ & $\begin{array}{c}0,1248 \\
(0,1292) \\
{[0,966]}\end{array}$ & $\begin{array}{c}0,4127 \\
(0,4751) \\
{[0,869]}\end{array}$ \\
\hline $\operatorname{DLM}(-2)$ & - & $\begin{array}{c}-0,2026 \\
(0,3693) \\
{[-0,559]}\end{array}$ \\
\hline $\operatorname{DLM}(-3)$ & - & $\begin{array}{c}-0,1525 \\
(0,3196) \\
{[-0,477]}\end{array}$ \\
\hline DLP & $\begin{array}{c}1,0844 \\
(0,0419) \\
{[25,9]}\end{array}$ & $\begin{array}{c}1,2191 \\
(0,1488) \\
{[8,19]}\end{array}$ \\
\hline $\operatorname{DLP}(-1)$ & $\begin{array}{l}-0,1211 \\
(0,1565) \\
{[-0,774]}\end{array}$ & $\begin{array}{c}-0,2953 \\
(0,4392) \\
{[-0,673]}\end{array}$ \\
\hline $\operatorname{DLP}(-2)$ & $\begin{array}{c}-0,0933 \\
(0,055) \\
{[-1,68]}\end{array}$ & $\begin{array}{c}0,095 \\
(0,3433) \\
{[0,278]}\end{array}$ \\
\hline $\operatorname{DLP}(-3)$ & $\begin{array}{c}-0,0605 \\
(0,046) \\
{[-1,31]}\end{array}$ & $\begin{array}{l}0,0558 \\
(0,236) \\
{[0,236]}\end{array}$ \\
\hline DLY & $\begin{array}{c}0,7469 \\
(0,3715) \\
{[2,01]}\end{array}$ & $\begin{array}{l}2,9818 \\
(1,632) \\
{[1,83]}\end{array}$ \\
\hline D1981 & $\begin{array}{c}-0,3813 \\
(0,1305) \\
{[-2,92]}\end{array}$ & - \\
\hline $\operatorname{ECM}(-1)$ & $\begin{array}{c}-0,8731 \\
(0,1604) \\
{[-5,44]}\end{array}$ & $\begin{array}{l}-1,698 \\
(0,667) \\
{[-2,55]}\end{array}$ \\
\hline
\end{tabular}




\begin{tabular}{lcc} 
(continuação) & & \\
\hline$\hat{\mathrm{u}}_{\mathrm{y}, \mathrm{t}}^{2}$ & $-26,325$ & $-29,782$ \\
& $(16,89)$ & $(24,43)$ \\
$\hat{\mathrm{u}}_{\mathrm{y}, \mathrm{t}-1}^{2}$ & {$[-1,56]$} & {$[-1,22]$} \\
& 12,295 & $-3,4942$ \\
$\hat{\mathrm{u}}_{\mathrm{y}, \mathrm{t}-2}^{2}$ & $(17,76)$ & $(23,59)$ \\
& {$[0,692]$} & {$[--0,148]$} \\
$\hat{\mathrm{u}}_{\mathrm{y}, \mathrm{t}-3}^{2}$ & 36,434 & 9,9438 \\
& $(18,56)$ & $(24,75)$ \\
& {$[1,96]$} & {$[0,402]$} \\
\hline Teste de exclusão (F): & $-4,047$ & 28,4835 \\
$\hat{\mathrm{u}}_{\mathrm{y}, \mathrm{t}}^{2} \hat{\mathrm{u}}_{\mathrm{y}, \mathrm{t}-1}^{2} ; \hat{\mathrm{u}}_{\mathrm{y}, \mathrm{t}-2}^{2} ; \hat{\mathrm{u}}_{\mathrm{y}, \mathrm{t}-3}^{2}$ & $(19,9)$ & $(23,2)$ \\
\hline
\end{tabular}

Fonte: Elaborada pelos autores.

\subsection{Teste de Assimetria sobre a Função de Oferta Nominal de Moeda}

A equação estimada na Tabela 9 restringe a velocidade de ajustamento $(\alpha)$ a ser idêntico quando o equilíbrio de longo prazo a ser corrigido é positivo ou negativo. Se o $\alpha$ for assimétrico em relação às mudanças no $E C M$, logo, a estimação da velocidade de ajustamento sob esta especificação pode estar errada.

Para determinar se o coeficiente do ECM é assimétrico para a função da oferta nominal de moeda, seguiu-se a metodologia sugerida em Pollard e Coughlin (2004). No sentido de verificar a assimetria do comportamento da transmissão da taxa de câmbio para o preço das importações, os autores substituíram $\beta_{1} \Delta e$ por $\beta_{1 A}(A \Delta e)+$ $\beta_{1 D}(D \Delta e)$ no qual A e D seriam, respectivamente, variáveis dummy referentes aos períodos de apreciação e de depreciação da taxa de câmbio. Formalmente, $A_{t}=1$ quando $\Delta e>0$ e 0 caso contrário; e $D_{t}=1$ quando $\Delta e<0$ e 0 caso contrário.

No presente estudo, o teste de assimetria de interesse é sobre a velocidade de ajustamento do termo que corrige o equilíbrio de longo prazo da função de oferta nominal de moeda.

Dessa forma, e assim como em Pollard e Coughlin (2004), para determinar se $\alpha$ é assimétrico em relação às correções positivas e negativas dos desvios do equilíbrio de longo prazo, duas variáveis dummies foram criadas na qual se separa os valores positivos do ECM dos negativos. Especificamente, para as equações estimadas na Tabela 9, seja:

$$
\begin{aligned}
& P_{t}=\begin{array}{l}
1 \text { quando } E C M_{t}>0 \\
0 \text { caso contrário }
\end{array} \\
& N_{t}=\begin{array}{l}
1 \text { quando } E C M_{t}<0 \\
0 \text { caso contrário }
\end{array}
\end{aligned}
$$


Interagindo essas variáveis dummies com o ECM e substituindo $\alpha E C M_{t-1}$ na Tabela 9 por $\alpha_{p}\left(P_{t-1} E C M_{t-1}\right)+\alpha_{N}\left(N_{t-1} E C M_{t-1}\right)$, resulta em uma estimação separada da velocidade de ajustamento sobre a correção positiva e negativa. $O$ teste de simetria consiste em verificar a seguinte restrição: $\alpha_{P}=\alpha_{N}$. Este teste está apresentado na Tabela 13.

Para o modelo de referência (M0) a Tabela 13 apresenta os resultados que indicam não assimetria do corretor de erros, uma vez que não se rejeita a hipótese de que os coeficientes dos desvios positivos e dos desvios negativos são iguais $\left(\alpha_{p}=\alpha_{N}\right)$.

Contudo, o teste de robustez parece indicar para uma certa assimetria do corretor de erros para o teste de robustez com o M4. Entretanto, a rejeição de Ho pode ser explicada pelo tamanho da amostra, visto que a disponibilidade de dados para o modelo com o M4 foi restrita (apenas 39 observações). Pode-se encontrar uma solução para esse problema assumindo a hipótese de que assintoticamente (ou, na medida em que a amostra cresce $-n$ tendendo ao infinito) o ECM converge para a simetria.

Tabela 13 - Teste de Wald de restrição: $\alpha_{\mathrm{P}}=\alpha_{\mathrm{N}}$

\begin{tabular}{ccccc}
\hline & $\begin{array}{c}\text { Hipótese Nula: } \\
\text { Restrição normalizada (=0) }\end{array}$ & Valor & Erro Padrão & Teste-t \\
\hline M0 & $\alpha_{\mathrm{P}}-\alpha_{\mathrm{N}}=0$ & 0,1862 & 0,3956 & 0,4707 \\
M4 & $\alpha_{\mathrm{P}}-\alpha_{\mathrm{N}}=0$ & 1,4022 & 0,6524 & 2,1493 \\
\hline
\end{tabular}

Fonte: Elaborada pelos autores.

Dessa forma conclui-se que o ECM é simétrico em relação à função de oferta nominal de moeda para o modelo com Mo, sendo que para o M4 tal resultado só poderá ser verdade assintoticamente. Em outras palavras, a velocidade de ajustamento do desvio da relação de longo prazo é a mesma quando esses desvios são positivos ou negativos.

\section{Considerações Finais}

A teoria econômica tradicional sugere que a política monetária pode afetar ciclos de negócios, mas não a tendência de crescimento de longo prazo da economia. Neste trabalho, investigou-se essa hipótese para a economia brasileira em período que abrange uma boa parte de vigência do Real, testando a existência de uma relação de longo prazo entre a oferta nominal de moeda e do produto real brasileiro. Em outras palavras, neste trabalho procurou-se apresentar testes de exogeneidade para o produto real na equação da oferta nominal de moeda. Para os teste foram considerados duas medidas de oferta monetária, Mo e M4, sendo o modelo principal com o Mo e o teste de robustez feito sobre o M4. 
O instrumental econométrico adotado neste trabalho tem a vantagem de não impor restrições sobre o número de defasagens utilizadas e principalmente, se preocupa em analisar a estrutura do modelo. Outra contribuição importante é a utilização de dados do PIB real brasileiro, aliado à baixa frequência dos dados anuais - e, ainda, com a amostra em um período que a política monetária sofreu profundas modificações, ou seja, o período pós-Real.

Uma discussão importante deste trabalho foi a estacionaridade da velocidade de circulação da moeda, que se mostrou ser estacionária apenas na presença de quebra. A construção de $v$ trouxe também implicações sobre a construção do termo de correção de erro e sobre o modelo de forma geral.

Os testes realizados parecem indicar para a exogeneidade fraca e a superexogeneidade do produto real sobre a função da oferta nominal de moeda, independentemente do agregado monetário estudado. $\mathrm{E}$ ainda, por meio do teste de assimetria, conclui-se que o $E C M_{t-1}$ é simétrico. Contudo, a hipótese de exogeneidade forte não foi conclusiva tendo em vista os resultados encontrados pelo teste de causalidade Granger. Em particular, discute-se na literatura a relação dos conceitos de exogeneidade com o conceito de causalidade no sentido de Granger. Nakane (1994), por exemplo, discutiu a impropriedade da identificação de testes de causalidade como testes de exogeneidade.

A relevância deste trabalho repousa na maior extensão da amostra, encobrindo um maior período de abrangência do Real, em que a política monetária sofreu profundas modificações. Contudo, a extensão da amostra parece não modificar os resultados empíricos encontrados na maioria das pesquisas internacionais, e principalmente, nacionais, ou seja, a hipótese da neutralidade da moeda não é rejeitada.

\section{Referências}

BAE, S.; RATTI, R. Long-run neutrality, high inflation, and bank insolvencies in Argentina and Brazil. Journal of Monetary Economics, Amsterdam, n. 46, p. 581-604, 2000.

BALL, L.; MANKIW, N.G. A sticky-price manifesto. NBER working paper, n. 4677, 1994.

BLANCHARD, O.; FISCHER, S. Lectures in Macroeconomics. Cambridge: The MIT Press, 1996.

BUENO, R. L. S. Econometria de séries temporais. São Paulo: Cengage Learning, 2008.

CASTRO, A. S.; CAVALCANTI, M. A. F. Estimação de equações de exportação e importação para o Brasil: 1955/95. Rio de Janeiro: IPEA, 1997. (Texto para Discussão, n. 469).

COE, P. J.; NASON, J. M. The long-horizon regression approach to monetary neutrality: how should the evidence be interpreted? Economics Letters, Amsterdam, n. 78, p. 351-356, 2002.

COOLEY, T. F.; LEROY, S. F. Atheoretical macroeconomics: a critique. Journal of Monetary Economics, Amsterdam, n. 16, p. 283-308, nov. 1985. 
DOORNIK, J. A. Autometrics. In: CASTLE, J. L.; SHEPHARD, N. The methodology and practice of econometrics. Oxford: Oxford University Press, 2009.

ENGLE, R. F.; HENDRY, D. F. Testing superexogeneity and invariance in regression models. Journal of Econometrics, Amsterdam, v. 56, n. 1-2, p. 119-139, 1993.

ENGLE, R. F.; HENDRY, D. F.; RICHARD, J. F. Exogeneity. Econometrica, Chicago, v. 51, n.2, p. 277-304, 1983.

FERNANDES, M.; TORO, J. O mecanismo de transmissão monetária na economia brasileira pós-plano Real. Revista Brasileira de Economia, Brasília, v. 59, n. 1, p. 5-32, 2005.

FISHER, M. E.; SEATER, J. J. Long-run neutrality and superneutrality in an ARIMA framework. American Economic Review, Princeton, v. 83, p. 402-415, 1993.

GRANGER, C. W. J.; HUANGB, B.-N.; YANG, C.-W. A bivariate causality between stock prices and exchange rates: evidence from recent Asianflu. Quarterly Review of Economics and Finance, Champaign, v. 40, n. 3, p. 337-354, 2000.

HAYO, B. Money- Output Granger causality revisited: an empirical analysis of EU countries. Applied Economics, v. 31, 1489-1501, 1999.

HENDRY, D. F.; MIZON, G. E. Evaluating dynamic econometric models by encompassing the VAR. Oxford: Institute of Economics and Statistics/University of Oxford, 1990. (Applied Economics Discussion Paper, n. 102).

JOHANSEN, S. Statistical analysis of cointegration vectors. Journal of Economic Dynamics and Control, St. Louis, v.12, p. 231-254, 1988.

KING, R. G.; PLOSSER, C. I. Money, credit and prices in a real business cycle. American Economic Review, Nashville, v. 74, p. 363-80, 1984.

KING, R. G.; WATSON, M. W. Testing long-run neutrality. Federal Reserve of Richmond Economic Quarterly, Richmond, v. 83, n. 3, p. 69-101, 1997.

KROLZIG, H. M.; HENDRY, D. F. We ran one regression. Oxford Bulletin of Economics and Statistics, Oxford, v. 66, n. 12, p. 799-810, 2004.

LEE, J.; STRAZICICH, M. C. Minimum lagrange multiplier unit root test with two structural breaks. Review of Economics and Statistics, Cambridge, v. 85, n. 4, p. 1082-1089, 2003.

LUCAS JUNIOR, R. E. Econometric policy evaluation: a critique. In: BRUNNER, K.; MELTZER, A. H. (Ed.). The Phillips Curve and labor markets. Amsterdam: North Holland, 1976.

MAGALHÃES, M. A. Equilíbrio e ciclos. Revista de Economia Contemporânea, Rio de Janeiro, v. 9, n. 3, p. 509-554, set./dez.2005.

MARQUES, G. O. C. A neutralidade monetária de longo-prazo no Brasil: uma análise simulatória utilizando índices de agregados monetários. 2003. Dissertação (Mestrado em Economia) - Faculdade de Economia, Administração e Contabilidade, Universidade de São Paulo, São Paulo, 2003.

NAKANE, M. I. Testes de exogeneidade forte e de superexogeneidade para a demanda por moeda no Brasil. 1994. Dissertação (Mestrado em Economia) - Faculdade de Economia e Administração, Universidade de São Paulo, São Paulo, 1994.

POLLARD, P.; COUGHLIN, C. Size matters: asymmetric exchange rate pass-through at the industry level. Working Paper Series, St. Louis, n. 13, July 2004.

ROMER, D. Advanced Macroeconomics. 3.ed. Boston: McGraw-Hill, 2005. 
SACHSIDA, A. Testes de exogeneidade sobre a correlação poupança doméstica e investimento. Brasília: IPEA, 1999 (Texto para Discussão, n. 659).

SERLETIS, A.; KOUSTAS, Z. International evidence on the neutrality of money. Journal of Money, Credit, and Banking, Columbus, v. 30, n. 1 p. 1-25, feb.1998.

SUMMERS, L. H. Optimal inflation policy. Journal of Monetary Economics, Cambridge, v. 7 , n. 2, p. 175-194, 1981.

TOBIN, J. Money and economic growth. Econometrica, Chicago, n. 33, p. 671-674, 1965.

Recebido em: 28/10/2010.

Aceito em: 15/09/2011. 